\title{
Amor con muchos matices y variantes: nuevo poemario de Concha Ortega
}

\section{Love with many nuances and variants: new poems by Concha Ortega}

\section{Miguel Gruz Giráldez}

Universidad de Sevilla (España)

mcruzg@us.es

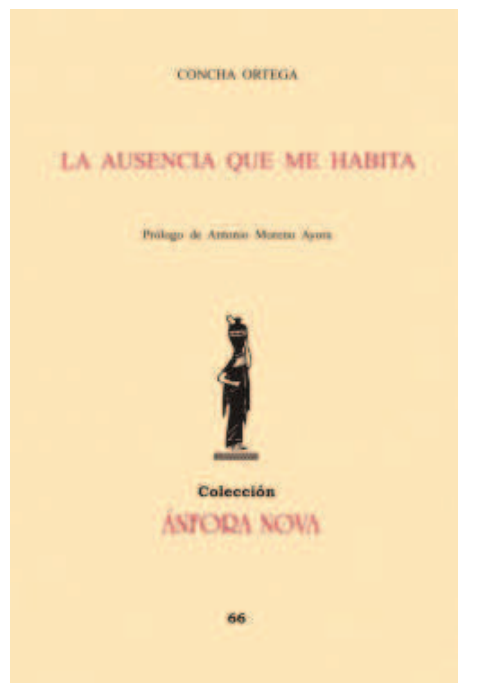

Reseña / Book Review: Concha (2019) La ausencia que me habita. Pról. Antonio Moreno Ayora. Rute (Córdoba): Ánfora Nueva, 82 p..

Un nuevo libro de poesía de la exquisita pintora y poeta Concha Ortega llega ahora al lector; un poemario primoroso, elegante, cuidado en todos los detalles, tanto externos como internos. La autora - reconocida y consagrada como una artista plástica de notable calidad- nos ofrece en este bello volumen poético otra muestra más de su extraordinaria sensibilidad. Nacida en Sevilla pero con infancia vivida en Ayamonte (Huelva), la presencia del mar, de los claros espacios abiertos, impregna toda su obra, tanto pictórica como lírica, aunque ambas se dan en ella estrechamente la mano para conformar un universo de gran colorido y belleza. Su temprana vocación por el mundo del Arte la hizo compaginar la práctica de la pintura en el estudio de Lola Martín con sus estudios de Delineación en Huelva y de 
Profesorado de Dibujo en Madrid. Ha sido Profesora de esta disciplina primero en el Instituto "Vélez de Guevara" de Écija, para pasar luego al Instituto de Bachillerato "San Fulgencio" de la misma ciudad, donde ha desarrollado la mayor parte de su vida docente y donde desempeñó la jefatura del Departamento de Dibujo hasta su jubilación y del que llegó a ser Vicedirectora. Como pintora, ha realizado numerosas exposiciones colectivas e individuales en galerías de arte y salas de exposiciones de toda la geografía nacional, y cuadros suyos forman parte de colecciones prestigiosas, tanto públicas como privadas. Concha Ortega -que es académica numeraria y actual directora de la Real Academia "Luis Vélez de Guevara" de Écija y además miembro correspondiente de las Reales Academias de Nobles Artes y Bellas Letras de Córdoba y de Bellas Artes "Santa Isabel de Hungría" de Sevilla- siempre ha compatibilizado su dedicación profesional a la docencia con la práctica artística y con la escritura. Fundó y dirigió la revista literaria de ámbito estudiantil Zarabanda (Instituto "San Fulgencio"). Colaboradora habitual en los diversos medios de comunicación de Écija (donde reside), su labor poética ha sido ya reconocida con importantes distinciones, como el primer premio de poesía en el Certamen Nacional "Santa Teresa de Jesús" otorgado por el Hogar de Ávila (Madrid, 2017). Entre sus obras de carácter lírico cabe destacar su participación en los volúmenes colectivos Hexaedro y Los anales diáfanos del viento, así como en el proyecto on line Retos poéticos. Colabora también en Cuadernos de Roldán y ha escrito en la antología de humanismo solidario Mano entregada, en la II Antología de la Asociación Colegial de Escritores de Andalucía No hay paisaje sin ti, que dirigen Manuel Gahete y Pedro Luis Ibáñez, y en la revista de poesía Piedra del Molino, dirigida por Jorge de Arco. En 2018 apareció su primer poemario ya en solitario, El lugar de las dudas, al que viene a sumarse el que ahora comentamos.

La ausencia que me habita es básicamente un libro de amor. El amor es, sin duda, el gran tema de la poesía universal, y desde luego es el eje central de la poesía de Concha Ortega. Amor con muchos matices y variantes: añoranza de lo que pudo ser y no fue, celos, recuerdos del pasado, desamor... La autora escribe desde la verdad de su alma, y desde la perspectiva de lo vivido, el sentimiento del amor adquiere un aire de verdad que nos estremece. Así lo vemos en títulos como "La llegada", "Amor ideal", "Contradicción" o "Mi secreto". Una inmensa mayoría de estos poemas suponen un fino análisis -autoanálisis- de los diversos estados de ánimo originados por el amor, cuyas vivencias llevan al sujeto poético a los caminos nostálgico del recuerdo ("La carta") o al afán de ruptura y libertad, e incluso a veces a evocar el paraíso perdido de la infancia ("El columpio"). Otros poemas hablan de la pintura ("Al color", "Pintando marinas", "A un pintor callejero", "Pintando al atardecer" o el espléndido "Danae y la lluvia de oro de Gustav Klimt"); de literatura ("Elena de Troya, ¿culpable o víctima?", "Madame Bovary", "La poesía” o "Al movimiento futurista"); o de bellas evocaciones artísticas ("Contemplando San Giorgio en Venecia o el clasicismo en la arquitectura de Palladio", "Contemplando el gótico cisterciense de Sacramenia" o "La fuente de las Ninfas de Écija"). Esto da 
al libro un tono ciertamente muy culturalista, en una línea plenamente inserta en la corriente "veneciana" de la poesía de los novísimos: un procedimiento renovador de la expresión de la intimidad y superador del intimismo primario, en la medida en que hace posible comunicar la experiencia cotidiana a través de lo cultural y evitar las limitaciones del yo lírico neorromántico. Y por eso no resulta aquí frío, pues permite a la autora hablar del yo enmascarándolo, y referirse a lo vital por medio de analogías. La autora designa entonces a un personaje histórico, literario o representado en una obra de arte, cuando quiere manifestar algo que se encuentra en una situación semejante a la suya; o bien se refiere a una obra literaria o artística cuando percibe que éstas significan algo idéntico o bien semejante a lo que quiere significar de sí misma.

Pero en el libro hay también otros registros temáticos. Así, visiones de la naturaleza, que se tiñen a veces de ecos románticos y modernistas, unos paisajes muy hermosos de primorosa sensualidad, tanto campestres ("La parra") como marinos: "Las olas de mi playa", "Las olas" o "Paseando al atardecer junto al río Guadiana". Frente a este mundo sosegado y pastoral, tampoco faltan las visiones urbanas deshumanizadoras ("Estrés" o "Escaparates"). Y no todo es puro intimismo, ya que hallamos asimismo composiciones que tratan sobre acontecimientos colectivos y ajenos en principio al sujeto lírico, como "Al huracán Irma", donde se lamenta la fuerza mortal de la naturaleza desatada contra los más desfavorecidos.

Y a estas alturas de su vida, la autora contempla la existencia con la serenidad que da el saber lo que de verdad es importante; así, "El tiempo en los espejos", "Mi partida" o "La ausencia que me habita" son excelentes testimonios de una sobria serenidad a la hora de afrontar el sentido de la existencia: en paz consigo misma y con el mundo que la rodea, la poesía de Concha Ortega la reconcilia -nos reconciliacon la edad y la belleza de lo cotidiano, con la sincera expresión de los sentimientos más humanos y profundos. De forma muy acertada, el último poema es el que da título a todo el libro; así se nos revela al final todo su sentido: vivir a cierta edad es ir conviviendo con las ausencias de tantos seres queridos que nos han acompañado a lo largo de nuestra andadura y que se han ido quedando en el camino. Y no hay por ello angustia, sino serena aceptación de una realidad inevitable.

Por último, desde el punto de vista de la teoría literaria, especial valor tienen los poemas "La poesía" y "A las palabras". En ellos, la autora explica cuál es su concepto de la escritura poética: la lírica entendida como una "explosión de sensaciones" y como un "elevarse en pos de un ideal". Un mundo que no existe si no se le nombra, de ahí el valor de la palabra, que es "comienzo y fin de todo lo creado".

La ausencia que me habita es formalmente un libro de modos clásicos: romances heroicos, liras y -sobre todo- sonetos. La mayoría de las sesenta y una composiciones que integran el libro son sonetos de distintas modalidades, lo que nos lleva a reflexionar sobre este hecho. 
El soneto es una de las formas poéticas de mayor raigambre y tradición en la lírica culta española. En su forma clásica, es una composición integrada por catorce versos endecasílabos, agrupados en dos cuartetos con las mismas rimas consonantes y dos tercetos, estos últimos de estructura variable. Aunque la distribución de su contenido no es exacta, puede decirse que el primer cuarteto plantea el tema del soneto y que el segundo lo desarrolla o lo amplifica. El primer terceto supone, por lo general, una reflexión sobre la idea central, o expresa algún sentimiento relacionado con el tema de los cuartetos; mientras que el segundo terceto -conclusivo- remata con un profundo sentimiento o una sentencia grave, que se desprenden en ambos casos del contenido de los cuartetos. De este modo, el soneto clásico presenta tres partes: una introducción, un desarrollo y una conclusión en el terceto final, que de alguna manera da sentido a todo el texto.

Es, pues, un poema completo, cerrado, que plantea, amplía y concluye cerrándolo- el motivo o el tema abordado. De ahí su éxito, pero también su dificultad. Nacido en la Italia prerrenacentista, fue cultivado en el siglo XIII por los poetas del dolce stil nuovo: Guido Guinizzelli, Guido Cavalcanti y Cino da Pistoia, entre otros, que utilizan ya los dos cuartetos y los dos tercetos. En el siglo XIV son relevantes los sonetos amorosos de Dante Alighieri, dedicados a su amada Beatrice Portinari y recogidos en su Vita nuova. Pero el mayor sonetista de esta etapa inicial fue sin duda Francesco Petrarca, en cuyo Cancionero aparece ya el soneto como la estructura poética más adecuada para expresar el sentimiento amoroso. A través del influjo de Petrarca, el soneto se extenderá al resto de las literaturas europeas.

En España, el primer intento significativo de adaptar el soneto a nuestra lengua es obra del Marqués de Santillana con sus cuarenta y dos Sonetos fechos al itálico modo, en la primera mitad del siglo XV. Pero fue con Garcilaso de la Vega -ya en el siglo XVI- cuando esta forma adquiere plena carta de naturaleza en la poesía española. Desde entonces hasta el Modernismo, el soneto castellano tuvo un esquema constructivo fijo en sus ocho primeros versos, y más libre en lo seis últimos. Todos los grandes poetas de los Siglos de Oro, del Neoclasicismo o del Romanticismo cultivaron con más o menos frecuencia el soneto. Sus temas son muy variados, desde el amoroso o el religioso al satírico, pasando por los morales y metafísicos, en los que sobresalió Quevedo. Durante todas estas etapas literarias, el soneto mantuvo en lo esencial su estructura clásica, a lo sumo con algunas pocas variantes como el soneto dialogado o el soneto con estrambote, que fueron introducidas por Cervantes.

La principal renovación del soneto en lengua española se produjo a fines del siglo XIX, con el triunfo del Modernismo. En el soneto modernista lo más usual es mantener el orden clásico en los cuartetos, aunque también -por influjo francésse cambian a veces las rimas de un cuarteto a otro, o se sustituyen los cuartetos por serventesios. El Modernismo renueva ciertamente la poesía hispánica, pero partiendo de la tradición. Así, en esta época se ensayan varias innovaciones métricas que afectarán al soneto: se usan versos de otras medidas, desde el tridecasílabo 
al hexadecasílabo, aunque los más utilizados son los alejandrinos, como los que emplea Rubén Darío en algunas de sus mejores composiciones; además aparecen sonetos polimétricos, y se rescata el sonetillo (soneto de arte menor, generalmente octosílabo), que tiene precedentes en los Siglos de Oro y el Neoclasicismo.

A partir de entonces, es muy frecuente el uso del soneto en la poesía contemporánea (Antonio y Manuel Machado, Juan Ramón Jiménez, los autores de la Generación del 27 fueron grandes sonetistas en la primera mitad del siglo XX). El soneto mantuvo también su vitalidad en la posguerra, gracias a poetas que lograron renovar su ritmo y retórica, como Blas de Otero, Ángel González o Carlos Edmundo de Ory. Y a pesar del auge de la poesía en verso libre, el soneto nunca ha faltado en la obra de los poetas andaluces actuales, especialmente sensibles al cuidado de la forma expresiva: Carlos Murciano, Antonio Carvajal o Jenaro Talens. Y algunos poetas posteriores a los Novísimos han retomado su cultivo, como Luis Alberto de Cuenca, con un rigor no exento de un tono humano e irónico.

Pues bien, en esta estela hay que situar a Concha Ortega, una de las mejores y más fervorosas sonetistas del panorama poético de hoy. En La ausencia que me habita hay todo tipo de sonetos, pues la autora es una hábil experimentadora de todas las formas posibles de este molde estrófico, que en sus manos deja de ser algo del pasado para convertirse en un instrumento muy adecuado para la expresión poética contemporánea. Encontramos sonetos octosílabos, endecasílabos, dodecasílabos y alejandrinos, con las rimas abrazadas o cruzadas, o sin rima; e incluso sonetos de pie quebrado, con el último verso de cada estrofa heptasílabo en vez de endecasílabo. Incluso hay experiencias muy curiosas, como lipogramas en los que falta sistemáticamente alguna vocal o consonante en todo el soneto; formas difíciles ("retos") que lejos de suponer un artificio antinatural constituyen moldes expresivos válidos para un discurso poético que no pierde nunca el sentimiento del calor humano.

Estamos, pues, ante una obra plenamente lograda. La elegancia de su formato, la distribución armónica de los espacios en sus páginas, el color del papel, la cuidada impresión de los poemas, todo contribuye en fin a gozar de su lectura, de la que -en las palabras del prologuista Antonio Moreno Ayora, que ofrece un estudio preliminar muy acertado-, "emerge una compenetración con sus significados y una aquiescencia que deja su mejor huella en nuestro ánimo". 